\title{
Analysis the Causes of Quality Defects in a Car Rack
}

\author{
Jacek Sitko ${ }^{1}$, Katarzyna Midor ${ }^{1}$ and T.N. Ivanova ${ }^{2,3, *}$ \\ ${ }^{1}$ Silesian Technical University, Roosevelt str. 26-28, 42-800 Zabrze, Poland \\ ${ }^{2}$ Tchaikovsky branch of Federal State Budgetary Educational Institution of Higher Education "Perm \\ National Research Polytechnic University”, Lenina st., 73, Tchaikovsky, 617764, Russia \\ ${ }^{3}$ Federal State Budgetary Institution of Science "Udmurt Federal Research Center of the Ural Branch \\ of the Russian Academy of Sciences“, Institute of Mechanics, 34, Tatyany Baramzinoi st., Izhevsk, \\ 426067, Russia
}

\begin{abstract}
The article contains an analysis of the problem related to manufacturing defects in the components of vehicle steering mechanism. Steps have been undertaken to identify the problem of quality defects occurrence by means of selected tools so as to reduce and eliminate such defects.
\end{abstract}

\section{Introduction}

The aim of the presented work is to analyse quality management methods and tools, which considerably contribute to solve quality problems at High Technology Automotive. Upon the management board's request, the name of the company has been changed. In the research part, particular operations of the production of toothed bars used in the car steering mechanism have been described.

The defects generated in the production process have been analysed. Using selected tools, the causes of defects have been identified and sorted in order to eliminate them.

\section{General characteristics of the methods and tools applied}

As the applied quality management tools are well-known and tested, the article contains only their brief characteristics, focused on their essential features.

The Pareto chart is based on an empirically discovered regularity that usually $20-30 \%$ of causes are responsible for 70-80\% of effects in man's activity [1].

An important issue is to properly identify the reasons responsible for major nonconformities. The Pareto method belongs to techniques which make it possible to determine activities aimed at improving the processes and quality attributes of material products and services. This method is used to identify the major features (events, causes), having the greatest impact on quality, which makes it a very useful tool for improving the quality of processes and selected quality features of material goods and services [2].

\footnotetext{
*Corresponding author: tatnic2013@yandex.ru
} 
This distribution can be referred to all phenomena and correlations which can be presented in figures and specified in terms of percentage. It is therefore used to assign particular importance to factors causing the problem. The following should be determined:

- Frequency of conducting an analysis;

- Manner of data sorting and recording;

- Frequency of recording;

- Scope of responsibility;

- Period the data refers to.

In order to achieve satisfying results, the following conditions should be fulfilled:

- The purpose of analysis is determined

- The problem is important

- All the people affected by the problem closely co-operate with one another.

Creating a Pareto chart requires taking appropriate steps in the following order [3, 4]:

- Define the purpose of study, e.g. reduction of the number of defects generated in production.

- Identify the data on the examined phenomenon which is related to a particular problem. In the data collection process the following should be determined:

- Determine the type and character of data;

- Establish the measurement unit for analysis, e.g. a specified number of events;

- Appoint persons responsible for data collection;

- Specify the period of time for which data will be analysed;

- Establish the manner of recording and storing the data;

- Create a table with the data put in order from the most to the least significant;

- Calculate percentage shares in relation to the whole phenomenon;

- Draw two vertical axes on both ends of a horizontal axis, which must be divided into segments the number of which corresponds to the number of causes.

The scale on the left axis should show the adopted measurement units. The height of this axis must equal the sum of all elements' values. On the other hand, the scale on the right vertical axis should be graduated from 0 to $100 \%$ and have the same height. On the vertical axis $\mathrm{Y}$ the total values of causes and their percentage shares should be marked. On axis $\mathrm{X}$ the causes, from the highest to the lowest total value, should be marked. For each of the causes, bar graphs should be drawn - a Pareto chart. The points corresponding to cumulative values should be mapped - a Pareto curve should be drawn. The obtained graph should be analysed in order to find the groups of causes to be investigated. First of all, conclusions on the improvement of the examined phenomenon should be formulated.

The ABC Method makes use of the ABC analysis to evaluate their value and usefulness for the company in the examined period of time. As an evaluation criterion we could use the competitive advantage, which can be expressed in cost leadership or wide product range. The latter is achieved owing to the flexibility of machines, which allows the company to frequently change the type and quality of a product. The ABC analysis is based on the Pareto principle, saying that each statistical group contains a few elements, symbolically marked as A, which determine the major part of results. On the other end of the distribution there are many elements of the group marked as $\mathrm{C}$, having a small share in the results of the activity, the work of which cannot be ignored, though. The remaining elements are indirect members of the group, marked with B. One of the applications of such categorization is the possibility to put technologies in order according to the purposefulness of developing and investing in such activities, that is to say, determining which technologies should be transferred to a higher level. Basic technologies belong to category A, fundamental for the company's activity. They are also referred to as driving technologies, as they help to provide a product 
with special attributes, e.g. a higher degree of surface smoothness [5]. Supporting technologies are important ones; they are frequently available to all companies in a particular branch of industry. Peripheral technologies are combined with basic technologies.

Peripheral technologies are usually a part of the company's general activity and are related to its own equipment. They include mainly technologies classified as category $\mathrm{C}$, which are usually not subject to the user's innovative activity [6].

The ABC Method can also be applied in materials management. The ABC analysis helps the purchase department of an enterprise to focus on the types of materials the deliveries of which have a big share in the overall value of the company's turnover [7].

Group A - „precious” stocks, which account for 5-20\% of the stocks assortment amount, but have a considerable share in the value, reaching $75-80 \%$;

Group B - stocks the share of which reaches $15-20 \%$, both in terms of stocks assortment amount and their value;

Group C - mass-produced stocks, having the largest share in the assortment amount - 60$80 \%$, and a very low share in the value - ca $5 \%$.

A histogram is a type of bar chart, applied in statistics to graphically present the frequency of a random variable within a particular interval. In the analysis of quality data, the histogram is used to visualise variability, e.g. of the results of a process or states of a particular feature of a product [8].

Histograms are helpful in an initial analysis of data, as they allow developing a pattern of distribution for a variable. On the horizontal axis the relevant class intervals are marked, while on the vertical axis the ordinates are mapped in such a way that the fields of relevant rectangles are proportional to the number of these features. Data contained in histograms is usually presented in a form of rectangular bars, also referred to as blocks, having equal width and different heights, which correspond to particular groups of information; they should also adhere to each other. The width represents an interval within the data range; the height represents the value of data within a particular interval [9].

Histograms can be effectively applied by repair teams when eliminating the defectiveness as well as improving the efficiency and quality of the product. To this end, relationships between tolerance, nominal measurement and the results achieved are examined; non-typical data is analysed and the causes of data distribution shape are checked [10].

The Ishikawa diagram allows putting the causes of irregularities in order and makes it possible to relate these causes by means of the simplest graphic form - a chart. These charts can be applied for examining various problems, characterised by a various degree of detail. Traditionally, they are used to solve quality problems involving a chain of causes [11].

These diagrams fulfil a number of functions and have numerous applications, e.g. [12]:

- They are used to record ideas;

- They help find the source of a problem;

- They help notice the complexity of a problem;

- They are a plan of map of an issue, which can be placed on the premises of the plant or in the office;

- They draw attention to important correlations.

The more knowledge and experience of different people is put into a chart, the more valuable it is, therefore, it is extremely important to analyse a problem in a wider circle (in the presence of production employees, technology specialists, sales department staff and organisers) [13].

Charts can be prepared on the basis of conversations between a leading person with each of the specialists separately or during a discussion of a specialist team. Owing to the first mentioned method, different people's proposals and opinions on the same subject can be compared. In this case mutual influence of the participants is eliminated, while the cycle of 
chart formation is lengthened. The second method is considered a more effective one, fulfilling its tasks.

A chart is prepared in the following order [14]:

First, the purpose of an activity of a problem must be specified. Place it on the main axis on the right. Next, identify the major causes in a „brainstorming” session. Put the causes in order according to categories. They should be grouped as very important and, affiliated to them, medium-important, whereas the less important causes should be affiliated to the medium-important ones. The significant causes should be placed closer to the main axis, while the less important ones - further. Next, have another discussion so as to find other causes, the least important for each category. Finish the diagram when the examined phenomenon is fully explored. The Ishikawa diagram should be updated on a continuous basis, depending on how many and which of the causes of the current errors has been removed or solved. The very use of the diagram does not allow the problem to be solved quickly. Creating a diagram is aimed at finding all possible reasons for the defects, so that the least probable ones can be eliminated in the future. Another elimination of the cause enables focusing on the most significant reasons for non-conformities and increases the chance of their detecting and removing [15].

The diagram construction based on the 5M Principle involves dividing it into 5 groups of causes.

They include [5]:

- Man - qualifications, habits, satisfaction with work, seniority, general physical and mental state.

- Method - procedures, instructions, scope of duties, specifications, norms, rules.

- Machine - licence, durability, modernity, efficiency, precision, safety, working conditions.

- Material - starting raw materials, semi-finished products, elements, substitutes.

- Management - organisational structure, work organisation, shift working.

Specifying the above causes is the result of general work experience when solving problems, using a dendrite diagram. Taking these groups into consideration provides a guarantee that the majority of important causes will be included in the diagram. However, in many cases it may be necessary to modify the above groups of causes, ignore some reasons and create new ones. Using the Ishikawa diagram in practice allowed determining the basic groups of causes responsible for quality problems $[16,17]$. The Ishikawa Diagram is a universal tool, which can be successfully used to find causes of various quality problems and specify the most important reasons [4].

\section{Characteristics of the firm}

Automotive firm is a producer of subassemblies, which are among others used in the production of steering mechanisms. The productions of columns and transmission gears takes place in other companies, and their manufacturers supply steering mechanisms for brands such as Opel, BMW and Mercedes. The main products of the company include pinions and toothed bars (Fig. 1), which are the main elements of steering gears. It is these elements that determine the correct functioning of the transmission gear. In this article the production line for manufacturing toothed bars has been described. The description is focused on the process, machines used on the line and defects generated in the process. The photograph below presents a toothed bar used in the production of steering gear. 


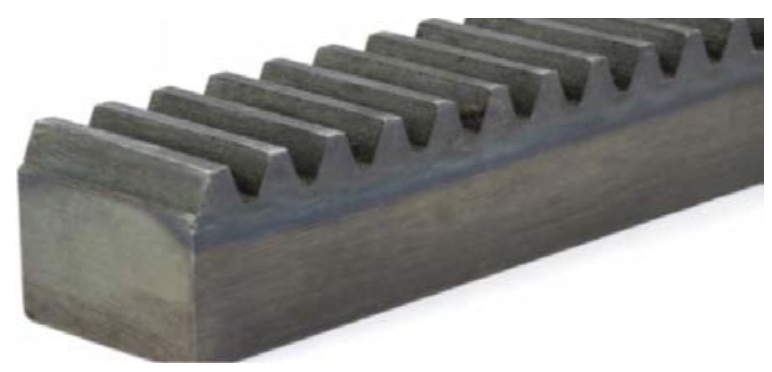

Fig. 1. Steering mechanism toothed bar [author's own study]

\section{Characteristics of the process}

First, the raw material is supplied from the warehouse to the production line. Parts are delivered in a form of pinions. The process starts with a centreless grinder. After grinding, the parts are transported by conveyor belts to the milling machine. In this operation the teeth are milled. The subsequent stage involves degreasing the workpieces in the process of washing, which is necessary as the grease used to cool the parts in the process of teeth milling has a negative impact on the quenched surface and may prevent the teeth from reaching the required hardness. The hardened bars are tempered in a furnace at $200^{\circ} \mathrm{C}$ for $2 \mathrm{~h} 30^{\prime}$. The aim of tempering is to get rid of stresses formed in the material in the process of hardening. After tempering the bars are cooled in a cooling tunnel. After cooling, the parts are straightened by means of an automatic straightener so as to ensure their appropriate rectilinearity. Rectilinearity influences the smooth work of the transmission gear. After straightening, the parts are checked for microcracks and surface defects. To do that, flaw detection testing is performed by the powder magnetic method. The penultimate operation is polishing, which provides the pinion surface with adequate roughness. Next, the workpieces are washed in a washer, with an addition of corrosion inhibitor. It protects the parts against corrosion in transport and enables their storage. At the end, final inspection is performed, the task of which is to check whether the parts have been made according to the customer's requirements.

\section{Selected testing methods applied in the process}

From deliveries to the plant to the final product, workpieces are subjected to inspection. After the parts have been delivered to the plant, the first measurement is taken by the quality control department. Due to the fact that there is no possibility to check all the delivered parts, a supplies control employee takes a random sample and checks if the product fulfils particular criteria. The number of parts taken from the delivery is not accidental. It is specified in the supplies control procedure. The amount of sample taken must guarantee the reliability of results. A quality control employee checks the parts mainly for the diameter, correct openings and threads in the front part of a pinion. If no non-conformities are found in an examined sample, the whole delivery is accepted. Sometimes a defect may be discovered in the process, which makes it easy to find that the supplier is to be blamed. In such a case the department withholds the whole batch and orders the parts to be sorted. Each delivery of the material is given an individual number, which allows determining its place of storage and the date of receipt. The company follows the FIFO principle (first in first out). The material is delivered in an appropriate order, starting with the oldest delivery. Each operation of the process uses different measuring methods and techniques. After grinding, an operator measures the diameter and roughness by means of measuring and control instruments. The workstation is equipped with both types of devices so that the two parameters can be monitored on a 
continuous basis. This is caused by the possibility of roughness worsening over a short period of time and by a narrow range of diameter dimensional tolerance. One measurement per shift is taken in the metallurgical laboratory so as to make sure there are no burns.

Detection of burns is possible owing to the etching method. It can be divided into the following stages:

- thorough cleaning and degreasing of the pinion;

- thorough rinsing;

- immersion in a $4 \%$ solution of nitric acid in alcohol for approximately 1 minute;

- rinsing;

- immersion in a 5\% solution of hydrochloric acid in alcohol for approximately 2 minutes;

- rinsing, immersion in a solution of ammonia or another neutralizing solution;

- rinsing in cold water;

- rinsing in hot water;

- drying with an air jet.

\section{The problem of product quality level}

At each stage of production, depending on the operation, methods aimed at maintaining the highest possible quality level are applied. The notion of quality is very broadly understood. First of all, it should be understood as the product's compliance with the customer's requirements, therefore, each operation/machine has a process card, which contains all the requirements, characteristics, measurement methods, people responsible for measurements, measurement frequency as well as drawing tolerances. Some part of inspection is performed on the spot, during the process, by the workstation employee. However, there are tests which, due to technical reasons and the lack of relevant trainings and licences, may not be conducted on the production line. They are, therefore, carried out by qualified staff in a laboratory.

Below have been presented defects occurring on particular machines.

Grinding:

- Improper workpiece diameter - it can be caused by many factors, usually due to insufficient dressing of the grinding wheel or improper arrangement of side bars.

- Improper roughness - its worsening is also influenced by the height at which the workpiece is placed.

- $\quad$ Damage to the workpiece front, badly placed side bars of the grinding machine, the workpiece, instead of getting between the wheel, first hits the grinding wheel.

- $\quad$ Burns - too low flow of the coolant or improper concentration of the cooling liquid.

- $\quad$ Burrs - too low concentration of the cooling liquid.

Milling:

- $\quad$ Burrs after milling - used milling cutter, improper regeneration.

- $\quad$ Chip imprints on the workpiece surface - badly positioned rinsing nozzles, used vice jaws, improper flow of oil.

- $\quad$ Burns - improperly regenerated milling cutter, low oil pressure.

- Improper roughness of teeth: excessive use of the milling cutter, badly adjusted milling parameters.

Quenching:

- $\quad$ Burns on the quenched surface - worn electrodes or improperly performed milling operation.

- $\quad$ Too little depth of quenching - excessive wear of electrodes.

- Hardening microcracks - e.g. improper concentration of the coolant, non-uniform cooling (obstructed openings in the shower).

Straightening: 
- Mechanical defects on the surface of workpiece subjected to straightening - it might be caused by excessive wear of the anvil or ram.

Polishing:

- High roughness on the surface - wear of the polishing wheel, improper roughness after grinding.

- $\quad$ Tarnish on the surface - worn polishing wheel.

On the basis of the below presented analysis of defects in the first six months (Tab. 1), five defects which caused the largest number of defected parts have been selected.

Table 1. Analysis of defects (author's own study)

\begin{tabular}{|c|c|c|c|c|c|c|c|}
\hline \multirow{2}{*}{ Type of defect } & \multicolumn{6}{|c|}{ Month } & \multirow[t]{2}{*}{ Summary } \\
\hline & $\mathrm{I}$ & II & III & IV & $\mathrm{V}$ & $\mathrm{VI}$ & \\
\hline Mechanical defects & 58 & 79 & 92 & 90 & 63 & 67 & 449 \\
\hline Scratches & 7 & 5 & 9 & 13 & 7 & 9 & 50 \\
\hline Small diameter after grinding & 11 & 12 & 10 & 8 & 11 & 15 & 67 \\
\hline Polishing - fall & 4 & 3 & 0 & 0 & 0 & 2 & 9 \\
\hline Exceeded rectilinearity & 12 & 17 & 10 & 11 & 0 & 2 & 52 \\
\hline $\begin{array}{c}\text { Damage caused by the straightening } \\
\text { machine }\end{array}$ & 17 & 0 & 0 & 0 & 4 & 3 & 24 \\
\hline Creases after milling & 49 & 55 & 56 & 71 & 53 & 36 & 320 \\
\hline Double engraving & 4 & 5 & 0 & 8 & 2 & 0 & 19 \\
\hline Creases caused by the screw & 23 & 0 & 0 & 0 & 0 & 0 & 23 \\
\hline Damaged thread & 6 & 5 & 11 & 9 & 4 & 4 & 39 \\
\hline $\begin{array}{c}\text { Failure to reach the cooling } \\
\text { temperature }\end{array}$ & 3 & 6 & 2 & 4 & 0 & 1 & 16 \\
\hline Max. power on the hardening table & 2 & 1 & 3 & 0 & 0 & 3 & 9 \\
\hline $\begin{array}{l}\text { Exceeded roughness } \\
\end{array}$ & 12 & 19 & 16 & 22 & 15 & 15 & 99 \\
\hline Hardening cracks & 0 & 0 & 5 & 0 & 0 & 0 & 5 \\
\hline Burns caused by hardening table & 4 & 2 & 0 & 3 & 0 & 2 & 11 \\
\hline
\end{tabular}

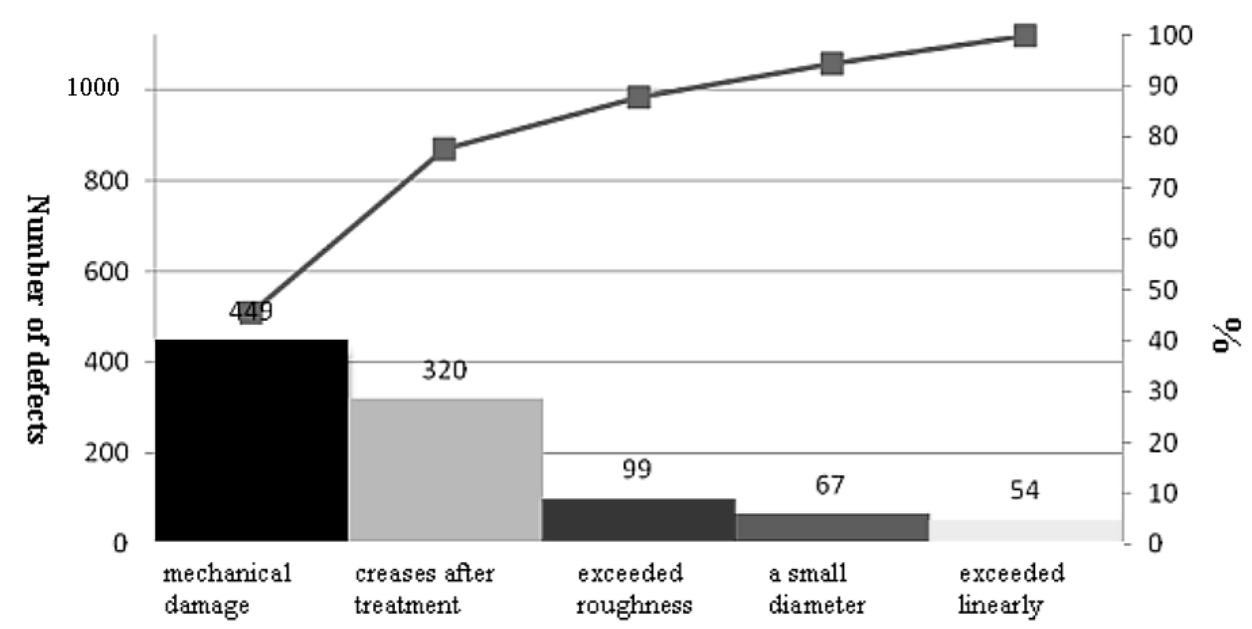

Fig. 2. Pareto chart (author's own study)

\section{Types of defects}


Based on the defects' analysis, a Pareto chart has been prepared (Fig. 2) to establish the causes which generate the biggest costs.

On the basis of the data contained in Table 1, it was found that two causes are responsible for $77.76 \%$ of the total number of non-conformities out of the five most frequently occurring in the process of toothed bar production: mechanical damages and creases after milling. Jointly they account for $40 \%$ of particular groups of non-conformity causes. To reduce the number of mechanical defects in the process, an Ishikawa diagram was prepared (Fig. 3), also referred to as a cause-and-effect diagram, the task of which was to establish all the causes.

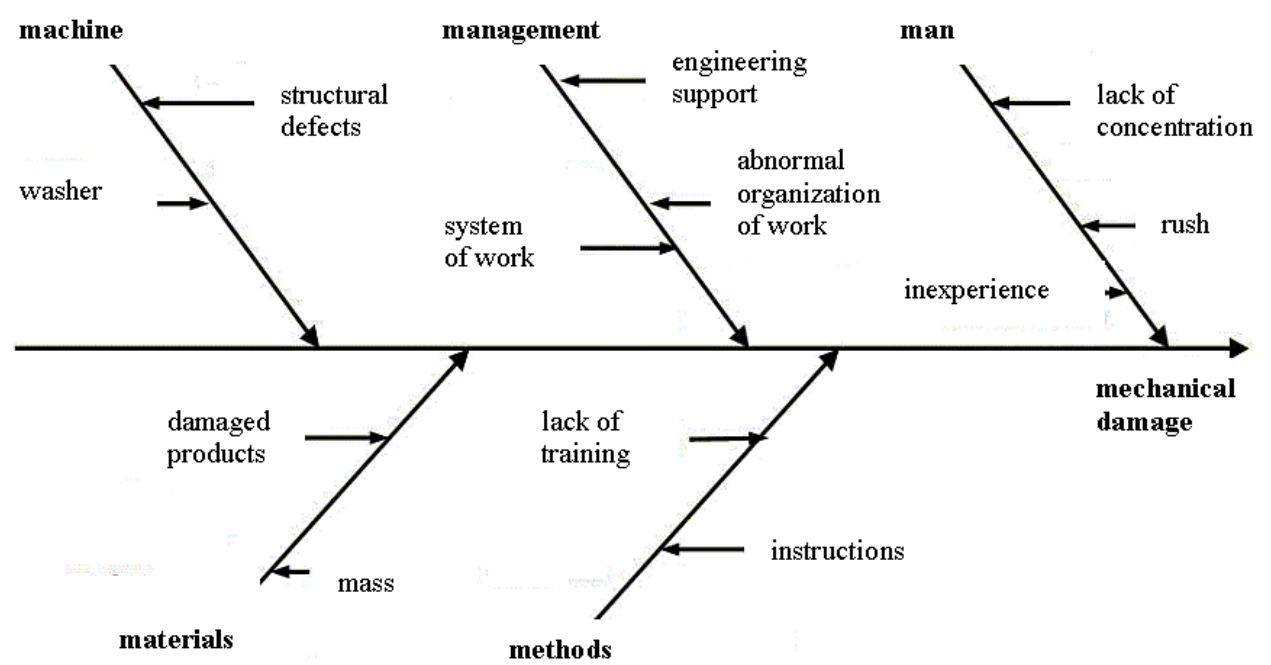

Fig. 3. Ishikawa diagram (author's own study)

On the basis of causes shown in the diagram, corrective measures were taken so as to eliminate and reduce the number of defects to minimum.

The machines were checked for sharp edges - potential places of defects. Plastic covers were put on slides and feeders. The tunnel washer rolls on which the pinions kept sliding were replaced. The workstation instructions were updated. A training course devoted to proper handling of parts and visual control were conducted for the employees.

Due to frequent rotation of employees, it was ordered that each new employee working at a particular workstation should be trained and acquainted with the instructions. New employees must work under the supervision of experienced operators.

The principle „One hand one part” was introduced, as there had been cases when the workers grabbed a few pinions at the same time, which generated defects.

In the area of management, times were measured in order to make a new calculation of the norms and an inspection of workstations was conducted in order to clear them of unnecessary elements. The inter-operational buffers were adjusted, as due to the lack of space, workpieces had been stored one on top of another one, which caused additional damage.

The supplier was informed of the necessity to change the packaging so as to better secure the pinions in transport. The undertaken measures helped to reduce the number of products rejected due to mechanical damage by $70 \%$.

The second type of defects which, as shown by the Pareto analysis, generated the biggest costs are creases formed in the milling process. The creases were caused by chips that remained in the vice; when the vice was clamped, the chip made an imprint on the pinion 
surface, causing its permanent damage. Such defects are unacceptable as it is on the surface where the thrust bearing works - the damage can shorten its life. The diagram below shows potential causes of such defects.

Corrective measures undertaken to minimize the defects:

- The coolant pump was changed for a higher-power pump in order to increase the pressure of oil in nozzles;

- Additional nozzles, responsible for flushing the vice in the process of workpiece loading, were mounted;

- A flow meter for monitoring the work of oil flow was installed;

- The life of vice jaws was determined, after making a particular number of pieces the jaws are replaced;

- An instruction for cleaning the machine elements such as: jaws, belt conveyors, milling cutter, drainage channels was introduced. It describes the manner and frequency of cleaning performed by an employee working with the machine;

- A new type of flushing nozzles was applied so that they could be positioned in a better way, as the high pressure caused that the previous nozzles changes the direction of flushing and the chips got between the vice jaws;

- An instruction obliging an employee to visually control the workpieces with a frequency of $1 / 5$ pieces was introduced. In the event a crease is discovered on the surface, the worker must immediately stop the milling process and clean the vice, vice jaws and belt conveyors.

\section{Summary}

1. The conducted studies revealed that the majority of defects can be avoided at the stage of process designing. Wrong construction of the machine was one of the key reasons for generating the costs. The price of a damaged product is PLN 100, which in a period of six months gives a loss of PLN 76900.

2. Using the Ishikawa diagram and Pareto chart brought the desired effect in a form of preventive measures. Despite the fact that the combination of these methods is timeconsuming and requires engagement of many employees from different departments, it turns out to be an effective way of solving production problems.

3. Each solution to a problem also contributes to the enhancement of employees experience; it teaches them how to use the available quality methods and tools and partly protects the organisation from complaints.

4. The level of quality depends among others on the policy and vision of an enterprise. Besides, a well-trained staff and investments in trainings upgrade the qualifications and increase the awareness of employees on their influence on the quality of products.

\section{References}

1. A. Hamrol, Zarządzanie jakością z przykładami. Wydawnictwo Naukowe PWN, 2014.

2. W. Biały, Wybrane zagadnienia $z$ wytrzymałości materiałów. Wydawnictwo WNT Warszawa, 2014.

3. W. Biały, J. Wedzicha,V. Nordin, Measurement of Weldings Incompatibility in Constructions. Multidisciplinary Aspectsof Production Engineering, 2018. 
4. W. Biały, J. Fries, Computer systems supporting the management of machines/equipment in hard coal mines. Case study. Management Systems in Production Engineering, Volume 27: Issue 3 2019, pp. 138-143.

5. Ł. Bołoz, K. Midor, Process innovations in mining industry and effect soft heir implementation presented on example of long wall milling heads, Acta Montanistica Slovaca, 2018.

6. P. Lowe, Zarządzanie technologią. Wydawnictwo Śląsk, Katowice, 1999.

7. P. Hąbek, Evaluation of sustainability reporting practices in Poland. Quality Quantity, 2014.

8. J. Sitko, Analiza możliwości przerobu produktów ubocznych wyrobów hutniczych. Systemy Wspomagania w Inżynierii Produkcji. 2015.

9. M. Gołębiowski, W. Jonasz, M. Prozorowicz, Zarządzanie jakością w przedsiębiorstwie. Wydawnictwo Naukowe Uniwersytetu Sczecińskiego, Szczecin, 1999.

10. B. Gajdzik, J. Sitko, An analysis of the causes of complaints about steel sheets in metallurgical product quality management systems. Metalurgija 53, 2014.

11. E. Kindlarski, Wykresy Ishikawy i Pareto. Zarządzanie przez jakość. Bellona, 1993.

12. E. Bank, Zarządzanie przez jakość. Wyd. Gebethner i Ska, Warszawa, 1996.

13. L. Wasilewski, Wartości Kaizen. Problemy jakości, 2, 1993.

14. A. Kleniewski, Uczmy się. Problemy jakości, 6, 1994.

15. W. Nierzwicki, Zarządzanie jakością. Ośrodek Doradztwa i Doskonalenia Kadr sp. z o.o. 1999.

16. K. Midor, B. Szczęśniak, M. Zasadzien, The metods of studying the satisfaction of production deartment with traffic maintenance department's work the out time of research method. Zeszyty Naukowe, Akademia Morska w Szczecinie, 2010.

17. N.F. Revenko, A.G. Skhirtladze, T.N. Ivanova and others Organization of production and management in mechanical engineering. Moscow, Higher school. 2010. 